\title{
BMJ Open Discovery of URAT1 SNPs and association between serum uric acid levels and URAT1
}

\author{
Sung Kweon Cho, ${ }^{1}$ Soriul Kim, ${ }^{2}$ Jae-Yong Chung, ${ }^{3}$ Sun Ha Jee ${ }^{2}$
}

To cite: Cho SK, Kim S, Chung J-Y, et al. Discovery of URAT1 SNPs and association between serum uric acid levels and URAT1. BMJ Open 2015:5:e009360.

doi:10.1136/bmjopen-2015009360

- Prepublication history for this paper is available online. To view these files please visit the journal online (http://dx.doi.org/10.1136/ bmjopen-2015-009360)

SHJ and J-YC are cocorresponding authors.

Received 13 July 2015 Revised 20 October 2015 Accepted 26 October 2015

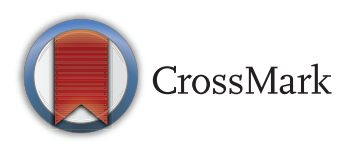

\footnotetext{
${ }^{1}$ Department of Pharmacology, Yonsei University College of Medicine, Seoul, Korea ${ }^{2}$ Department of Epidemiology and Health Promotion and Institute for Health Promotion, Graduate School of Public Health, Yonsei University College of Medicine, Seoul, Republic of Korea

${ }^{3}$ Department of Clinical Pharmacology and Therapeutics, Seoul National University College of Medicine and Bundang Hospital, Seongnam, Korea
}

Correspondence to Dr Sun Ha Jee; jsunha@yuhs.ac

\section{ABSTRACT}

Objectives: Human urate transporter 1 (URAT1) is a member of the organic anion transporter family (SLC22A12) that primarily regulates the renal tubular reabsorption of uric acid. This case-control study was designed to analyse whether hURAT1 might also be a candidate gene for hyperuricaemia or hypouricaemia.

Setting: We recruited 68 healthy volunteers and divided them into two groups: a normal uric acid group and a hyperuricaemia group. We analysed the sequence of the URAT1 gene and found five significant single nucleotide polymorphisms (SNPs). We then selected 900 male subjects from the 262200 enrolled in the Korean Cancer Prevention Study-II (KCPS-II) cohort for further genetic analysis.

Participants: DNA samples from 36 individuals with normal uric acid $(<4.5 \mathrm{mg} / \mathrm{dL})$ and 32 individuals with hyperuricaemia $(>8.5 \mathrm{mg} / \mathrm{dL}$ ) were sequenced. Five significant SNPs (rs7929627, rs75786299, rs3825017, rs11602903 and rs121907892) were identified. We then chose 900 subjects from the KCPS-II cohort consisting of 450 subjects with normal uric acid (UA $<4.1 \mathrm{mg} / \mathrm{dL}$ ) and 450 subjects with hyperuricaemia (UA $>8.7 \mathrm{mg} / \mathrm{dL}$ ). The groups were matched by age, body mass index, metabolic syndrome and use of antihypertensive medication.

Primary outcome measures: We compared the $\mathrm{OR}$ of the incidence of hyperuricaemia by URAT1 genotype.

Results: The strongest association with hyperuricaemia was observed for rs75786299 (IVS3 $+11 \mathrm{~A} / \mathrm{G}$ ) with an OR of 32.05. rs7929627 (IVS7-103A/ G) and rs3825017 (N82N) showed an association with hyperuricaemia with ORs of 2.56 and 2.29 , respectively. rs11602903 (788A/T) and rs121907892 (W258X) were negatively correlated with hyperuricaemia with ORs of 0.350 and 0.447 , respectively. Individuals carrying the GATAG haplotype $(n=32)$ - a relatively common variant consisting of rs7929627, rs75786299 and rs3825017 - showed the highest risk for hyperuricaemia with an OR of $92.23\left(p=9.55 \times 10^{-3}\right)$.

Conclusions: These results indicate that five newly described SNPs in the hURAT1 gene are significantly associated with uric acid level (4-2008-0318 and 42011-0277).

\section{INTRODUCTION}

Uric acid is the final metabolic product of purine nucleotides in humans. An elevated

\section{Strengths and limitations of this study}

- This study provides new understanding of asymptomatic hyperuricaemia observed during clinical trial screenings or regular medical checkups.

- This study was well powered and well controlled: 900 subjects selected from the Korean Cancer Prevention Study-II cohort, were divided into a hyperuricaemia group $(n=450)$ and a normal group ( $n=450)$, and matched for age, body mass index, metabolic syndrome and use of antihypertensive medication.

- The result of this study is limited to healthy Korean subjects with hyperuricaemia.

- Longitudinal and disease-course studies are needed to evaluate the relevance of URAT1 SNPS in gout and other metabolic diseases.

level of serum uric acid is a risk factor for gout. ${ }^{1}$ Uric acid is produced primarily in the liver, and two-thirds of it is excreted via the kidney. A deficit in uric acid excretion results in hyperuricaemia, leading to diseases such as gout. On the other hand, an increase in uric acid excretion causes urolithiasis. The uric acid transport system of renal proximal tubules plays an important role in the determination of serum uric acid levels. ${ }^{1}$ Uric acid enters the proximal tubules in its anion form. In humans, uric acid is almost fully reabsorbed through the kidney; only $10 \%$ of filtered acid is secreted. ${ }^{2}$ Absence of the enzyme uricase and the presence of an effective renal anion transport system contribute to higher uric acid levels in humans than in other mammals. ${ }^{3}{ }^{4}$ Uric acid serum level in the general population follows a normal distribution. ${ }^{1}$ The intake of purines or fructose may influence serum uric acid level. Genetic factors may explain the critical process of uric acid reabsorption and its role in hyperuricaemia. The heritability of uric acid serum concentration has previously been estimated to be $40-70 \% .{ }^{5}$ Strong evidence of this can be seen in studies ${ }^{7}$ and segregation analysis in 
families. ${ }^{8}$ Kottgen et at ${ }^{\ominus}$ recently reported that 28 genetic loci could explain the observed $6 \%$ variance in uric acid in European Caucasian subjects. The most influential loci, as one might expect, encode proteins involved in secretion and renal filtration of uric acid. Since Enomoto et $a l^{10}$ identified the urate transporter in the human kidney (URAT1, encoded by SLC22A12), a urate-anion exchanger localised on the apical side of the proximal tubule, many genome-wide association studies (GWAS) and target SNP studies have found significant polymorphisms in different ethnic groups. ${ }^{1-15}$ The most frequent mutation, W258X for hypouricaemia, and other hypouricaemia-related SNPs in Japanese patients, were not found in German or Czech Caucasians subjects. ${ }^{16} 17$ It is well known that W258X (rs121907892) is associated with hypouricaemia in Korean individuals. ${ }^{12}$ Recently, a high frequency of SLC22A12 variants (c.1245_1253del and c. $1400 \mathrm{C}>\mathrm{T} ; 1.87 \%$ and $5.56 \%$, respectively) which contribute to renal hypouricaemia was reported in the Roma population. ${ }^{18}$ Our aim was to clarify the association of URAT1 with serum uric acid in Korean subjects. In this study, we conducted full direct sequencing in 68 healthy Korean subjects (36 with uric acid levels below $4.5 \mathrm{mg}$ / $\mathrm{dL}(0.076 \mu \mathrm{mol} / \mathrm{L})$ and 32 with uric acid levels above $8.5 \mathrm{mg} / \mathrm{dL}(0.14 \mu \mathrm{mol} / \mathrm{L}))$. After selection of a tagging SNP, we validated the five significant URAT1 SNPs in 900 men chosen from the Korean Cancer Prevention Study-II (KCPS-II) cohort.

\section{MATERIALS AND METHODS}

\section{Discovery of URAT1 variants by direct sequencing}

Sixty-eight male genomic DNA samples were selected from healthy individuals from the DNA bank of Severance hospital, Seoul, Korea (4-2008-0318) taking into account uric acid level (36 subjects with levels below $4.5 \mathrm{mg} / \mathrm{dL}(0.076 \mu \mathrm{mol} / \mathrm{L})$ and 32 subjects with levels above $8.0 \mathrm{mg} / \mathrm{dL}(0.13 \mu \mathrm{mol} / \mathrm{L}))$. Ethics approval was obtained from Severance institutional review board and all participants provided informed consent. The health status of each individual was evaluated by routine physical examination and laboratory tests. Participants were divided into two groups: a normal uric acid group that included hypouricaemic individuals, and a hyperuricaemia group. To identify genetic variants of URAT1, the entire 5802 bp URAT1 gene including the coding region, flanking intronic sequences and $3^{\prime}$ UTR region was amplified and sequenced using an automated genetic analyzer (Applied Biosystems, Foster City, California, USA). Haplotype assembly was performed using the programme Haploview (V.4.2; developed by the Broad Institute, Cambridge, Massachusetts, USA). Nucleotide location numbers were assigned from the translational start site (GenBank accession number: AB071863).

\section{SNP selection}

Study-specific association analyses for sequencing the data of the 68 subjects were performed using linear regression for uric acid, assuming an additive genetic model. For uric acid, the covariates were age and body mass index (BMI). Excluding SNPs of less than 1\% allele frequency, we selected eight SNPs as tagging SNPs with high linkage disequilibrium (LD) $\left(r^{2}>0.8\right)$. Among these eight SNPs, five URAT1 SNPs significant for uric acid were selected as candidate SNPs for the replication cohort.

\section{Data collection of replication cohort}

The KCPS-II cohort consisted of 262200 participants who were given routine health examinations at health promotion centres in South Korea from 1994 to 2012. Baseline data were collected by trained interviewers. Information on socio-demographic factors, health status and lifestyle was included in the questionnaires. A general health examination was performed at the same time. Standing height, body weight and waist circumference were measured with participants wearing light indoor clothing and without shoes. BMI was calculated as weight in kilograms divided by height in metres squared. For each individual, blood was drawn after at least $8 \mathrm{~h}$ of fasting for whole blood and serum samples. Uric acid, creatinine, triglyceride, total cholesterol, low density lipoprotein (LDL) cholesterol, high density lipoprotein (HDL) cholesterol and blood glucose levels were measured using an Hitachi-7600 analyzer. Nine hundred male subjects were selected from the KCPS-II cohort according to the following criteria: (1) 450 subjects with a uric acid level below $4.1 \mathrm{mg} / \mathrm{dL}$ (normal group including hypouricaemia) and 450 subjects with a uric acid level above $8.7 \mathrm{mg} / \mathrm{dL}$ (hyperuricaemia group); and (2) age, BMI and subjects with metabolic syndrome or taking anti-hypertensive drugs were equally distributed into the two separate groups. All 900 subjects agreed to provide DNA samples (4-2011-0277). To optimise the effect of the URAT1 SNPs, other factors affecting uric acid were balanced between the two groups.

\section{Association analysis}

After ensuring demographic similarity between the two groups (table 1), we estimated the effects of five significant URAT1 SNPs on uric acid as an OR using a multivariate binary logistic regression method. BMI, systolic blood pressure, diastolic blood pressure, total cholesterol, triglyceride, fasting glucose, LDL cholesterol, HDL cholesterol and creatinine are included as covariates. Pearson's $\chi^{2}$ test was used to calculate the allelic risk of hyperuricaemia. The data were analysed using SPSS software V.18 (SPSS, Chicago, Illinois, USA). In general, $p$ values of $<0.05$ were considered statistically significant, but we used adjusted $\mathrm{p}$ values based on the Bonferroni correction when we performed multiple statistical tests simultaneously.

\section{Haplotype association analysis}

Haplotype imputation by expectation maximisation was performed in PLINK to produce the most likely 
Table 1 Demographic characteristics

\begin{tabular}{|c|c|c|c|}
\hline Characteristics & Normal uric acid group & High uric acid group & Total \\
\hline Discovery stage & $\mathrm{n}=36$ & $\mathrm{n}=32$ & $\mathrm{n}=68$ \\
\hline Age, years & $28 \pm 4$ & $28 \pm 3$ & $28 \pm 4$ \\
\hline $\mathrm{BMI}, \mathrm{kg} / \mathrm{m}^{2}$ & $24.00 \pm 2.01$ & $22.24 \pm 2.19$ & $23.07 \pm 2.27$ \\
\hline \multirow[t]{2}{*}{ Uric acid, mg/dL* } & $3.91 \pm 0.64$ & $8.71 \pm 0.77$ & $6.17 \pm 2.51$ \\
\hline & $(0.066 \pm 0.011 \mu \mathrm{mol} / \mathrm{L})$ & $(0.15 \pm 0.013 \mu \mathrm{mol} / \mathrm{L})$ & $(0.10 \pm 0.042 \mu \mathrm{mol} / \mathrm{L})$ \\
\hline Replication stage & $n=450$ & $n=450$ & $\mathrm{n}=900$ \\
\hline Age, years & $44 \pm 8$ & $44 \pm 8$ & $44 \pm 8$ \\
\hline $\mathrm{BMI}, \mathrm{kg} / \mathrm{m}^{2 \star}$ & $27.18 \pm 1.96$ & $27.53 \pm 2.19$ & $27.35 \pm 2.09$ \\
\hline Waist circumference, $\mathrm{cm}$ & $91.70 \pm 6.08$ & $92.39 \pm 6.12$ & $92.04 \pm 6.10$ \\
\hline \multicolumn{4}{|l|}{ Blood pressure, $\mathrm{mm} \mathrm{Hg}$} \\
\hline Systolic* & $124.90 \pm 12.54$ & $127.80 \pm 13.66$ & $126.31 \pm 13.18$ \\
\hline Diastolic* & $79.96 \pm 9.21$ & $81.84 \pm 9.63$ & $80.90 \pm 9.47$ \\
\hline \multicolumn{4}{|l|}{ Smoking status } \\
\hline Never smokers, n (\%) & $103(25.06)$ & $112(13.69)$ & $215(26.28)$ \\
\hline Ever smokers, n (\%) & $308(74.94)$ & $295(72.48)$ & 603 (73.72) \\
\hline \multicolumn{4}{|l|}{ Alcohol consumption } \\
\hline Never drinkers, n (\%) & $50(11.99)$ & $54(13.20)$ & 104 (12.59) \\
\hline Ever drinkers, $\mathrm{n}(\%)$ & $367(88.01)$ & $355(86.80)$ & $722(87.41)$ \\
\hline \multirow[t]{2}{*}{ Uric acid, $\mathrm{mg} / \mathrm{dL}^{*}$} & $3.59 \pm 0.47$ & $9.45 \pm 0.57$ & $6.52 \pm 2.98$ \\
\hline & $(0.060 \pm 0.0079 \mu \mathrm{mol} / \mathrm{L})$ & $(0.16 \pm 0.0096 \mu \mathrm{mol} / \mathrm{L})$ & $(0.11 \pm 0.050 \mu \mathrm{mol} / \mathrm{L})$ \\
\hline Total cholesterol, mg/dL* & $201.00 \pm 35.00$ & $213.90 \pm 36.00$ & $207.45 \pm 36.07$ \\
\hline Triglycerides, mg/dL* & $198.60 \pm 112.90$ & $248.40 \pm 143.30$ & $223.50 \pm 131.11$ \\
\hline Fasting glucose, $\mathrm{mg} / \mathrm{dL}^{*}$ & $110.70 \pm 41.40$ & $96.59 \pm 13.97$ & $103.63 \pm 31.67$ \\
\hline LDL cholesterol, mg/dL* & $118.50 \pm 33.20$ & $126.50 \pm 35.12$ & $122.61 \pm 34.41$ \\
\hline HDL cholesterol, mg/dL* & $47.78 \pm 10.84$ & $45.63 \pm 9.02$ & $46.71 \pm 10.02$ \\
\hline Creatinine, $\mathrm{mg} / \mathrm{dL}^{*}$ & $1.07 \pm 0.15$ & $1.26 \pm 0.26$ & $1.16 \pm 0.23$ \\
\hline \multicolumn{4}{|c|}{$\begin{array}{l}\text { Values are mean } \pm \text { SD for continuous data. } \\
{ }^{*} \mathrm{p}<0.05 \text {, comparing the normal uric acid level group }(<4.5 \mathrm{mg} / \mathrm{dL}(<0.076 \mu \mathrm{mol} / \mathrm{L}) \text { (discovery stage) and }<4.1 \mathrm{mg} / \mathrm{dL}(<0.069 \mu \mathrm{mol} / \mathrm{L}) \\
\text { (replication stage)) and high uric acid level group }(>8.5 \mathrm{mg} / \mathrm{dL}(>0.14 \mu \mathrm{mol} / \mathrm{L}) \text { (discovery stage) and }>8.7 \mathrm{mg} / \mathrm{dL}(>0.15 \mu \mathrm{mol} / \mathrm{L})(\mathrm{replication} \\
\text { stage)). } \\
\text { Body mass index (BMI) was calculated as weight in kilograms divided by height in metres squared. } \\
\text { HDL, high density lipoprotein; LDL, low density lipoprotein. }\end{array}$} \\
\hline
\end{tabular}

haplotype calls. These data were then used to perform a BMI, systolic blood pressure, diastolic blood pressure, total cholesterol, triglyceride, fasting glucose, LDL cholesterol, HDL cholesterol and creatinine-adjusted logistic regression in PLINK, producing ORs and $\mathrm{p}$ values.

\section{Locus-specific hyperuricaemia genetic risk score and} correlation with uric acid level

We used the simple count method to calculate the genetic risk score (GRS) of five URAT1 SNPs. In case of loss-of-function URAT1 polymorphism, a score of 3 was assigned to those homozygous for the reference allele, 2 to heterozygotes, and 1 to those homozygous for the loss-of-function allele. In case of gain-of-function URAT1 polymorphism, 1 was assigned to those with the reference allele, 2 to heterozygotes, and 3 to those homozygous for the gain-of-function allele. In this study the GRS ranges from 3 to 15 . Subjects were divided into four groups of 225 each based on GRS score, from low to high. The GRS distribution of the four groups was: $0<\mathrm{GRS}<5.0,5.0 \leq \mathrm{GRS}<6.0,6.0 \leq \mathrm{GRS}<7.0$ and $7.0 \leq \mathrm{GRS}$. Where the hyperuricaemia group and the normal group had the same GRS, we estimated the incremental GRS quintile effect on hyperuricaemia versus the normal ratio with reference to the Q1 group. The attenuation of the association of GRS of the hyperuricaemia group versus the normal group in a balanced demographic sampling from the cohort suggests a causal association between URAT1 SNPs and uric acid. ${ }^{19}$

\section{RESULTS}

URAT1 SNP discovery and association analysis with uric acid

Whole sequencing of URAT1 was performed in 68 male Korean subjects, divided into a hyperuricaemia group and a normal control group (including hypouricaemia). Sequencing revealed 26 SNPs in the URAT1 gene (table 2). Our study is the first to identify one SNP in the promoter region (c.-46G $>\mathrm{A}$ ) and three non-coding variants $($ c.506+32T $>\mathrm{C}$, c.662-18C $>\mathrm{G}$ and c.1395-105C $>\mathrm{T})$ of URAT1. Excluding mono call error, we conducted a correlation analysis of 26 URAT1 SNPs with uric acid (data not shown). We plotted 19 URAT1 SNPs, excluding SNPs of less than $1 \%$ allele frequency. From $19 \mathrm{SNPs}$, we selected eight SNPs as tagging SNPs with high LD $\left(r^{2}>0.8\right)$. The eight SNPs are rs11602903, rs7929627, rs476037, rs373337426, rs75786299, rs148845071, rs3825017 and 
rs121907892. rs11602903 represents rs974313, rs3825016, rs3825018, rs524023, rs11231825, rs1529909, rs2021860 and rs559946. rs7929627 represents rs11231837 and rs7932775. rs476037 represents rs3832794. Five tagging SNPs (rs7929627, rs75786299, rs3825017, rs11602903 and rs121907892) significantly associated with uric acid were selected for replication.

\section{Genotype associations and allelic associations}

We examined the relationship between the five selected URAT1 SNPs and hyperuricaemia incidence in the discovery and replication stage of this study (table 3). All five selected SNPs showed a significant $(\mathrm{p}<0.05)$ association with uric acid level in the discovery stage (data not shown). In the replication stage, it was observed that subjects heterozygous or homozygous for rs7929627 were more likely to be hyperuricaemic than those in the control group $(\mathrm{OR}=2.41, \quad 95 \%$ CI 1.79 to 3.22 , $\mathrm{p}=3.57 \times 10^{-9}$ and $\mathrm{OR}=7.86,95 \%$ CI 4.85 to 12.7 , $\mathrm{p}=3.33 \times 10^{-14}$, respectively). Subjects heterozygous for rs75786299 were more likely to be hyperuricaemic than those in the control group $(\mathrm{OR}=33.22,95 \%$ CI 4.51 to $\left.244.43, \mathrm{p}=9.30 \times 10^{-9}\right)$. Subjects heterozygous or homozygous for rs3825017 were more likely to be hyperuricaemic than those in the control group $(\mathrm{OR}=2.38,95 \% \mathrm{CI}$ 1.76 to $3.20, \mathrm{p}=1.07 \times 10^{-8}$ and $\mathrm{OR}=4.23,95 \%$ CI 1.96 to $9.11, \mathrm{p}=1.12 \times 10^{-4}$, respectively). Subjects heterozygous or homozygous for rs11602903 were less likely to be hyperuricaemic than those in the control group $\left(\mathrm{OR}=0.25,95 \%\right.$ CI 0.19 to $0.34, \mathrm{p}=1.70 \times 10^{-14}$ and $\mathrm{OR}=0.17, \quad 95 \% \quad$ CI $\quad 0.10 \quad$ to $0.29, \quad \mathrm{p}=1.93 \times 10^{-12}$, respectively).

Three SNPs (rs7929627, rs75786299 and rs3825017) were associated with a gain-of-function mutation
$(\mathrm{OR}=2.37, \mathrm{p}=0.015 ; \mathrm{OR}=1.09, \mathrm{p}=0.016 ;$ and $\mathrm{OR}=3.13$, $\mathrm{p}=0.009$; rs7929627, rs75786299 and rs382501, respectively) in the discovery stage. All three showed the same results in the replication phase $\left(\mathrm{OR}=2.56, \mathrm{p}=3.84 \times 10^{-14}\right.$; $\mathrm{OR}=32.07, \mathrm{p}=1.20 \times 10^{-8}$; and $\mathrm{OR}=2.29, \mathrm{p}=3.44 \times 10^{-11}$; rs7929627, rs75786299 and rs3825017, respectively). Individuals who had the rs75786299 polymorphism showed the highest OR for hyperuricaemia. Two SNPs (rs11602903 and rs121907892) were associated with a loss-of-function mutation $\quad(\mathrm{OR}=0.45, \quad \mathrm{p}=0.048$ and $\mathrm{OR}=0.915, \quad \mathrm{p}=0.017 ; \quad \mathrm{rs} 11602903$ and $\mathrm{rs} 121907892$, respectively). These two SNPs induced hypouricaemia (rs11602903, rs121907892; OR $=0.350, \mathrm{p}=3.60 \times 10^{-14}$ and $\mathrm{OR}=0.447, \mathrm{p}=1.10 \times 10^{-14}$, respectively) in the replication cohort as well.

\section{Haplotype association analysis}

We performed logistic regression analysis to evaluate the association between the incidence of hyperuricaemia and haplotype of the five selected SNPs with reference to the AGCAG haplotype. Haplotype AGCAG SNPs are rs7929627, rs75786299, rs3825017, rs11602903 and rs121907892. Haplotype GGCAG contains one gain-of-function SNP, rs7929627, and is associated with a significantly increased incidence of hyperuricaemia ( $p=0.035 ; O R=1.48)$. Haplotype GGTAG contains two gain of function SNPs, rs7929627 and rs3825017, and is associated with a significantly increased incidence of hyperuricaemia $(\mathrm{p}=0.011$; OR=1.64). Haplotype GATAG contains three gain-of-function SNPs, rs7929627, rs75786299 and rs3825017, and is associated with a significantly increased incidence of hyperuricaemia $\left(\mathrm{p}=9.55 \times 10^{-3} ; \mathrm{OR}=92.23\right)$. Haplotype AGCAA contains one loss-of-function SNP, rs121907892, and is associated

Table 2 Frequency of URAT1 genetic variations in Korean subjects

\begin{tabular}{|c|c|c|c|c|c|c|c|}
\hline rs number & Variant & $\begin{array}{l}\text { Amino acid } \\
\text { substitution }\end{array}$ & $\begin{array}{l}\text { Minor allele } \\
\text { frequency }\end{array}$ & rs number & Variant & $\begin{array}{l}\text { Amino acid } \\
\text { substitution }\end{array}$ & $\begin{array}{l}\text { Minor allele } \\
\text { frequency }\end{array}$ \\
\hline \multicolumn{8}{|c|}{ Promoter variants } \\
\hline rs11602903 & c. $-788 A>T$ & & 0.265 & rs559946 & c. $-424 \mathrm{C}>\mathrm{T}$ & & 0.265 \\
\hline rs524023 & c. $-764 \mathrm{C}>\mathrm{T}$ & & 0.265 & rs3825018 & c. $-220 A>G$ & & 0.265 \\
\hline rs9734313 & c. $-718 \mathrm{C}>\mathrm{T}$ & & 0.265 & - & c. $-46 G>A$ & & 0.007 \\
\hline \multicolumn{8}{|l|}{ Coding variant } \\
\hline rs3825017 & c. $246 C>T$ & $\mathrm{~N} 82 \mathrm{~N}$ & 0.224 & rs121907893 & c. $650 \mathrm{C}>\mathrm{T}$ & T217M & 0.007 \\
\hline rs3825016 & c. $258 \mathrm{C}>\mathrm{T}$ & $\mathrm{H} 86 \mathrm{H}$ & 0.265 & rs121907892 & c. $774 \mathrm{G}>\mathrm{A}$ & W258X & 0.044 \\
\hline rs11231825 & c. $426 \mathrm{~T}>\mathrm{C}$ & $\mathrm{H} 142 \mathrm{H}$ & 0.265 & rs7932775 & c. $1309 \mathrm{~T}>\mathrm{C}$ & L437L & 0.427 \\
\hline \multicolumn{8}{|c|}{ Non-coding variants } \\
\hline- & c. $506+32 T>C$ & & 0.007 & rs78880801 & c. $1070+66 C>T$ & & 0.008 \\
\hline rs75786299 & c. $661+11 \mathrm{G}>\mathrm{A}$ & & 0.037 & rs373337426 & c. $1071-33 \mathrm{C}>\mathrm{T}$ & & 0.022 \\
\hline- & c. $662-18 C>G$ & & 0.007 & rs7929627 & c. $1286-103 A>G$ & & 0.427 \\
\hline rs2021860 & c. $830+109 \mathrm{G}>\mathrm{T}$ & & 0.265 & - & c. $1395-105 C>T$ & & 0.007 \\
\hline rs1529909 & c. $831-45 \mathrm{~T}>\mathrm{C}$ & & 0.273 & rs11231837 & c. $1598+18 C>T$ & & 0.427 \\
\hline \multicolumn{8}{|c|}{$3^{\prime}$ UTR variants } \\
\hline rs139299506 & c. ${ }^{*} 163 d e l T C$ & & 0.007 & rs3832794 & c. ${ }^{\star 291 d e l G}$ & & 0.316 \\
\hline rs148845071 & c. ${ }^{\star} 268 \mathrm{G}>\mathrm{A}$ & & 0.037 & rs476037 & c. ${ }^{\star} 517 \mathrm{G}>\mathrm{A}$ & & 0.316 \\
\hline
\end{tabular}

Data were obtained from DNA samples from 68 unrelated Korean individuals.

The position of the variant is based upon the translational start site. 


\begin{tabular}{|c|c|c|c|c|c|c|c|}
\hline \multirow{2}{*}{$\begin{array}{l}\text { SNP amino acid change } \\
\text { (rs number) }\end{array}$} & \multirow[b]{2}{*}{ Genotype } & \multirow{2}{*}{$\begin{array}{l}\text { Normal uric } \\
\text { acid group }\end{array}$} & \multirow{2}{*}{$\begin{array}{l}\text { High uric } \\
\text { acid group }\end{array}$} & \multicolumn{2}{|c|}{ Allele frequency } & \multirow[b]{2}{*}{ Allele OR $(95 \% \mathrm{Cl})$} & \multirow[b]{2}{*}{$p$ Value } \\
\hline & & & & Control & Case & & \\
\hline Discovery stage & & $\begin{array}{l}\mathrm{UA}<4.5 \mathrm{mg} / \mathrm{dL} \\
(<0.076 \mu \mathrm{mol} / \mathrm{L})\end{array}$ & $\begin{array}{l}\mathrm{UA}>8.5 \mathrm{mg} / \mathrm{dL} \\
(>0.14 \mu \mathrm{mol} / \mathrm{L})\end{array}$ & & & & \\
\hline \multirow[t]{3}{*}{ IVS7-103A/G (rs7929627) } & AA & 17 & 7 & \multirow[t]{3}{*}{0.32} & \multirow[t]{3}{*}{0.53} & 2.37 (1.18 to 4.76$)$ & \multirow[t]{3}{*}{0.015} \\
\hline & $A G$ & 14 & 16 & & & $(R: A)$ & \\
\hline & GG & 5 & 9 & & & & \\
\hline \multirow[t]{2}{*}{ IVS3+11A/G (rs75786299) } & GG & 36 & 27 & \multirow{2}{*}{0} & \multirow[t]{2}{*}{0.08} & 1.09 (1.01 to 1.17$)$ & \multirow[t]{2}{*}{0.016} \\
\hline & GA & 0 & 5 & & & (R: G) & \\
\hline \multirow[t]{3}{*}{ N82N (rs3825017) } & $\mathrm{CC}$ & 27 & 13 & \multirow[t]{3}{*}{0.13} & \multirow[t]{3}{*}{0.31} & $3.13(1.30$ to 7.52$)$ & \multirow[t]{3}{*}{0.009} \\
\hline & CT & 9 & 17 & & & (R: C) & \\
\hline & TT & 0 & 2 & & & & \\
\hline \multirow[t]{3}{*}{$-788 \mathrm{~A} / \mathrm{T}$ (rs11602903) } & AA & 15 & 21 & \multirow[t]{3}{*}{0.34} & \multirow[t]{3}{*}{0.19} & 0.452 (0.204 to 1.003$)$ & \multirow[t]{3}{*}{0.048} \\
\hline & AT & 18 & 10 & & & $(R: A)$ & \\
\hline & TT & 3 & 1 & & & & \\
\hline \multirow[t]{3}{*}{ W258X (rs121907892) } & GG & 30 & 32 & \multirow[t]{3}{*}{0.09} & \multirow[t]{3}{*}{0} & 0.915 (0.853 to 0.983$)$ & \multirow[t]{3}{*}{0.017} \\
\hline & GA & 6 & 0 & & & (R: G) & \\
\hline & $A A$ & 0 & 0 & & & & \\
\hline \multicolumn{2}{|l|}{ Replication stage } & $\begin{array}{l}\mathrm{UA}<4.1 \mathrm{mg} / \mathrm{dL} \\
(<0.076 \mu \mathrm{mol} / \mathrm{L})\end{array}$ & $\begin{array}{l}\mathrm{UA}>8.7 \mathrm{mg} / \mathrm{dL} \\
(<0.076 \mu \mathrm{mol} / \mathrm{L})\end{array}$ & & & & \\
\hline IVS7-103A/G (rs7929627) & AA & 236 & 119 & \multirow[t]{3}{*}{0.27} & 0.48 & 2.56 (2.10 to 3.12$)(\mathrm{R}: \mathrm{A})$ & $3.84 \times 10^{-14}$ \\
\hline & $A G$ & 188 & 228 & & & & \\
\hline & GG & 26 & 103 & & & & \\
\hline IVS3+11A/G (rs75786299) & GG & 449 & 419 & $<0.01$ & 0.03 & 32.07 (4.37 to 235.44$)$ & $1.20 \times 10^{-8}$ \\
\hline & GA & 1 & 31 & & & (R: G) & \\
\hline N82N (rs3825017) & $\mathrm{CC}$ & 345 & 254 & 0.13 & 0.25 & 2.29 (1.78 to 2.93$)$ & $3.44 \times 10^{-11}$ \\
\hline & CT & 96 & 168 & & & (R: C) & \\
\hline & TT & 9 & 28 & & & & \\
\hline$-788 \mathrm{~A} / \mathrm{T}$ (rs11602903) & $\mathrm{AA}$ & 136 & 292 & 0.42 & 0.20 & 0.350 (0.284 to 0.432$)$ & $3.60 \times 10^{-14}$ \\
\hline & AT & 253 & 136 & & & $(R: A)$ & \\
\hline & TT & 61 & 22 & & & & \\
\hline W258X (rs121907892) & GG & 282 & 450 & 0.19 & 0 & 0.447 (0.424 to 0.472$)$ & $1.10 \times 10^{-14}$ \\
\hline & GA & 164 & 0 & & & (R: G) & \\
\hline & $A A$ & 4 & 0 & & & & \\
\hline
\end{tabular}

$\mathrm{p}$ Value is determined by Pearson's $\chi^{2}$ test in the allele analysis.

$\mathrm{R}$, reference allele. 
with the absence of hyperuricaemia. Haplotype AGCTA contains two loss-of-function SNPs, rs11602903 and rs121907892, and is associated with the absence of hyperuricaemia. Haplotypes AGCTG and GGCTG were not significantly different from the reference haplotype.

\section{Gout GRS association}

A simple GRS was calculated to determine the cumulative effect of the URAT1 SNPs. In each set, the incidence of hyperuricaemia was significantly higher than the GRS of the control group (Q1) (table 4). We found a correlation between GRS and incidence of hyperuricaemia (Q1 vs Q2, Q1 vs Q3 and Q1 vs Q4; OR $=4.00$, $\mathrm{p}=2.00 \times 10^{-6} ; \quad \mathrm{OR}=5.78, \mathrm{p}=4.50 \times 10^{-10} ;$ and $\mathrm{OR}=15.62$, $\mathrm{p}=1.94 \times 10^{-25}$, respectively).

\section{DISCUSSION}

We found significant uric acid-related URAT1 SNPs that differed between hyperuricaemic and normal or hypouricaemic subjects. Five selected SNPs from the discovery stage showed a significant association with uric acid in the 900 replication cohort subjects. In the haplotype analysis, the OR for the incidence of hyperuricaemia was gradually increased when an individual carried one gain-of-function SNP, two SNPs or three SNPs $(\mathrm{OR}=1.48$, 1.64 and 92.23 respectively). On the other hand, the OR decreased when an individual had one loss-of-function SNP or two such SNPs (OR=0.86 and 0, respectively). Finally, we investigated the effect of URAT1 on uric acid using GRS analysis (table 4).

Founder mutation rs $121907892^{20}$ showed the strongest association with hypouricaemia in our study. In the replication cohort, the uric acid level in individuals homozygous (AA) for rs121907892 was $1.85 \pm 0.17 \mathrm{mg} / \mathrm{dL}(0.031$ $\pm 0.0029 \mu \mathrm{mol} / \mathrm{L}$ ), while the uric acid of subjects homozygous (AA) for rs121907892 was below $2 \mathrm{mg} / \mathrm{dL}$ $(0.034 \mu \mathrm{mol} / \mathrm{L})$. Interestingly, Korean subjects with the rs11602903 allele were at an increased risk for hypouricaemia, whereas Graessler et $a l^{16}$ reported that the AA genotype of rs11602903 in German subjects was associated with reduced renal uric acid excretion $(\mathrm{OR}=1.8$, $95 \%$ CI 1.129 to $2.993, p=0.0139$ for fractional excretion of uric acid). Decreased renal uric acid excretion implies increased URAT1 activity, which should correlate

Table 4 Adjusted ORs and 95\% Cls for the hyperuricaemia group versus the normal group ratio by genetic risk score (GRS) of URAT1 SNP among 900 subjects

\begin{tabular}{lrlll}
\hline $\begin{array}{l}\text { GRS } \\
\text { quartile }\end{array}$ & OR & 95\% Cl & p Value & $\begin{array}{l}\text { p For } \\
\text { trend }\end{array}$ \\
\hline Q1 & 1.00 & & & \\
Q2 & 4.00 & 2.26 to 7.08 & $2.00 \times 10^{-6}$ & \\
Q3 & 5.78 & 3.33 to 10.04 & $4.50 \times 10^{-10}$ & $1.18 \times 10^{-31}$ \\
Q4 & 15.62 & 9.32 to 26.19 & $1.94 \times 10^{-25}$ & \\
\hline
\end{tabular}

with higher uric acid levels. Considering the difference in allele frequency in the two ethnic groups, the risk associated with the allele is comparable. $\mathrm{Li}$ et $a l^{21}{ }^{21}$ studying a Chinese population, showed that people with the rs11602903 allele had an increased incidence of hypouricaemia. Our tagging SNP, rs7929627, a SNP in intron 7, is genetically identical to rs7932775, a SNP in exon 8. Han Chinese individuals carrying rs7932775 were at increased risk for hyperuricaemia. ${ }^{21} \mathrm{~A}$ recent report on a Caucasian Czech population did not show any significant difference in serum uric acid level associated with rs7932775. Since our replication set focused instead on rs7929627, it is difficult to explain this discrepancy between studies in Caucasian and Asian populations. Further investigation is needed.

Although rs3825017 was not significantly associated with uric acid levels in the Chinese study, ${ }^{21}$ it showed a strong association in our study $(\mathrm{OR}=2.29,95 \%$ CI 1.78 to 2.93, $\left.\mathrm{p}=3.44 \times 10^{-11}\right)$. Because the population size of the present study was much larger, it is likely that we observed real effects that would not otherwise have been statistically significant. rs75786299 is the SNP most strongly associated with hyperuricaemia in our study $(\mathrm{OR}=32.07,95 \%$ CI 4.37 to $235.44, p=3.44 \times 10^{-11}$ ). Because of its low allelic frequency (1.8\% in Korean subjects), this SNP was not identified by any previous GWAS study. Further functional study is needed to confirm our results, although Lee $e t a l^{12}$ investigated the prevalence of hypouricaemia and its association with two URAT1 SNPs (W258X and $\mathrm{R} 90 \mathrm{H}$ ) in healthy Korean subjects. To the best our knowledge, this is the first study to sequence the entire URAT1 gene and investigate these five tagging SNPs and their association with uric acid levels in Korean subjects.

Our study has some limitations. First, we could not find previously identified missense and frame shift mutations with lower allelic frequencies: R90H, V138M, G164S and T217M. ${ }^{16}$ This may be explained by population selection as we did not recruit patients with nephrolithiasis and low uric acid. Further study is needed to investigate patients with nephrolithiasis and low uric acid to demonstrate consistency with the previous report. ${ }^{20}$ Second, we could not evaluate all of the significant SNPs from the discovery stage. Since coverage of our five tagged SNPs is in the high LD region $\left(r^{2}=0.8\right)$, other SNPs might show different results in the replication stage. However, we are confident that these five selected SNPs convincingly illustrate an association of URAT1 with uric acid level in Korean subjects. Third, our study results have not been confirmed in patients with gout or nephrolithiasis. A logical next step is to investigate URAT1 SNP association with gout and nephrolithiasis.

We conclude that the haplotype association of our five selected URAT1 SNPs with hyperuricaemia has a potential predictive benefit. We found the hyperuricaemia related variant in the combined analysis (GATAG; $\mathrm{OR}=92.23, \mathrm{p}=0.0096$ ), which is associated with a high risk of gout in Korean subjects. We also found the hypouricaemic related variant (AGCTA), which is associated with a high risk for nephrolithiasis. ${ }^{20}$ To validate a 
genetic marker for future risk prediction for gout or nephrolithiasis, a large data association study is required that investigates the prevalence of our SNPs in gout patients or subjects who have had kidney stones.

Contributors SKC, J-YC, SHJ: participated in research design; SKC, SK: conducted the study; SKC, SK, J-YC: performed data analysis; SKC, SK, J-YC, SHJ: wrote or contributed to the writing of the manuscript.

Funding This study was supported by the Seoul City R \& BD programme (grant no. 10526) and grants (A111218-PG03) from the National Project for Personalized Genomic Medicine under the Ministry for Health and Welfare of the Republic of Korea. We appreciate the kind support of Eunsoon Shin, DNA Link, Inc.

Competing interests None declared.

Patient consent Obtained.

Ethics approval Severance hospital institutional review board approved this study.

Provenance and peer review Not commissioned; externally peer reviewed.

Data sharing statement No additional data are available.

Open Access This is an Open Access article distributed in accordance with the Creative Commons Attribution Non Commercial (CC BY-NC 4.0) license, which permits others to distribute, remix, adapt, build upon this work noncommercially, and license their derivative works on different terms, provided the original work is properly cited and the use is non-commercial. See: http:// creativecommons.org/licenses/by-nc/4.0/

\section{REFERENCES}

1. Riches PL, Wright AF, Ralston SH. Recent insights into the pathogenesis of hyperuricaemia and gout. Hum Mol Genet 2009;18: R177-84.

2. Anzai N, Kanai $\mathrm{Y}$, Endou $\mathrm{H}$. New insights into renal transport of urate. Curr Opin Rheumatol 2007;19:151-7.

3. Bobulescu IA, Moe OW. Renal transport of uric acid: evolving concepts and uncertainties. Adv Chronic Kidney Dis 2012;19:358-71.

4. Wu XW, Muzny DM, Lee CC, et al. Two independent mutational events in the loss of urate oxidase during hominoid evolution. $J \mathrm{Mol}$ Evol 1992;34:78-84.

5. Nath SD, Voruganti VS, Arar NH, et al. Genome scan for determinants of serum uric acid variability. J Am Soc Nephrol 2007;18:3156-63.

6. Yang Q, Guo C, Cupples LA, et al. Genome-wide search for genes affecting serum uric acid levels: the Framingham Heart Study. Metabolism 2005;54:1435-41.
7. Emmerson BT, Nagel SL, Duffy DL, et al. Genetic control of the renal clearance of urate: a study of twins. Ann Rheum Dis 1992;51:375-7.

8. Wilk JB, Djousse L, Borecki I, et al. Segregation analysis of serum uric acid in the NHLBI Family Heart Study. Hum Genet 2000;106:355-9.

9. Kottgen A, Albrecht E, Teumer A, et al. Genome-wide association analyses identify 18 new loci associated with serum urate concentrations. Nat Genet 2013;45:145-54.

10. Enomoto A, Kimura $\mathrm{H}$, Chairoungdua A, et al. Molecular identification of a renal urate anion exchanger that regulates blood urate levels. Nature 2002;417:447-52.

11. Zar ZM, Eloranta J, Stieger B, et al. Pharmacogenetics of OATP (SLC21/SLCO), OAT and OCT (SLC22) and PEPT (SLC15) transporters in the intestine, liver and kidney. Pharmacogenomics 2008;9:597-624.

12. Lee $\mathrm{JH}$, Choi HJ, Lee BH, et al. Prevalence of hypouricaemia and SLC22A12 mutations in healthy Korean subjects. Nephrology (Carlton) 2008;13:661-6.

13. Takahashi T, Tsuchida S, Oyamada T, et al. Recurrent URAT1 gene mutations and prevalence of renal hypouricemia in Japanese. Pediatr Nephrol 2005;20:576-8.

14. Jang WC, Nam Y, Park S, et al. T6092C polymorphism of SLC22A12 gene is associated with serum uric acid concentrations in Korean male subjects. Clin Chim Acta 2008:398:140-4.

15. Shafiu M, Johnson RJ, Turner ST, et al. Urate transporter gene SLC22A12 polymorphisms associated with obesity and metabolic syndrome in Caucasians with hypertension. Kidney Blood Press Res 2012;35:477-82.

16. Graessler J, Graessler A, Unger S, et al. Association of the human urate transporter 1 with reduced renal uric acid excretion and hyperuricemia in a German Caucasian population. Arthritis Rheum 2006;54:292-300.

17. Hurba $\mathrm{O}$, Mancikova $\mathrm{A}$, Krylov $\mathrm{V}$, et al. Complex analysis of urate transporters SLC2A9, SLC22A12 and functional characterization of non-synonymous allelic variants of GLUT9 in the Czech population: no evidence of effect on hyperuricemia and gout. PLOS ONE 2014;9:e107902.

18. Gabrikova D, Bernasovska J, Sokolova J, et al. High frequency of SLC22A12 variants causing renal hypouricemia 1 in the Czech and Slovak Roma population; simple and rapid detection method by allele-specific polymerase chain reaction. Urolithiasis 2015;2:2.

19. Lawlor DA, Harbord RM, Sterne JA, et al. Mendelian randomization: using genes as instruments for making causal inferences in epidemiology. Stat Med 2008;27:1133-63.

20. Ichida K, Hosoyamada M, Hisatome I, et al. Clinical and molecular analysis of patients with renal hypouricemia in Japan-influence of URAT1 gene on urinary urate excretion. J Am Soc Nephrol 2004;15:164-73.

21. Li C, Han L, Levin AM, et al. Multiple single nucleotide polymorphisms in the human urate transporter 1 (hURAT1) gene are associated with hyperuricaemia in Han Chinese. J Med Genet 2010;47:204-10. 